\title{
Serious adverse drug reactions with hydroxychloroquine: a pharmacovigilance study in Vigibase ${ }^{\circledast}$
}

\author{
Jean-Louis Montastruc ${ }^{1}$ (D) Vanessa Rousseau ${ }^{1} \cdot$ Geneviève Durrieu $\cdot$ Haleh Bagheri ${ }^{1}$
}

Received: 13 April 2020 / Accepted: 27 May 2020 / Published online: 6 June 2020

(C) Springer-Verlag GmbH Germany, part of Springer Nature 2020

Hydroxychloroquine is a chloroquine derivative, widely used in rheumatoid arthritis or lupus [1]. Following pilot observational studies, it has been recently proposed (alone or with azithromycin) in COVID-19 patients despite lack of clinical evidence $[2,3]$. Using an old drug in a new disease means evaluation of benefits but also risks. Although several adverse drug reactions (ADRs) were described with hydroxychloroquine, there are no general data about their relative frequency and occurrence. Recent development of large databases in pharmacovigilance offers new opportunities to investigate the safety profile of such candidate drugs [4]. It was the aim of this study to investigate the safety profile of hydroxychloroquine (alone or with azithromycin).

The study was performed in Vigibase $®$, the WHO pharmacovigilance database, which registers all Individual Case Safety Reports (ICSRs) from more than 130 countries [5]. We extracted all ICSRs registered as "serious" and "suspected/interacting" between 1 January 2010 and 31 December 2019 and including men or women aged $\geq 18$ years. ICSRs in patients with age and sex unknown or registered as malformations, medication errors, or treatment failure were excluded. We describe the main characteristics of patients (age, sex) and kind of ADRs (classified according to Standardized MedDRA Queries (SMQs), classification). A special attention was given to lethal ICSRs and those with hydrochloroquine + azithromycin $(\mathrm{H}+\mathrm{A})$ [2].

There were 5219 ICSRs in Vigibase $\AA, 82.1 \%$ in women, mean age $54.3 \pm 15.4$ [18-95], $25.6 \%$ between 18 and 64 years, $46.5 \%$ between 45 and 64 years, $19.2 \%$ between 65

Jean-Louis Montastruc

jean-louis.montastruc@univ-tlse3.fr

1 Service de Pharmacologie Médicale et Clinique, Centre de PharmacoVigilance, de Pharmacoépidémiologie et d'Informations sur le Médicament, Faculté de Médecine, Centre Hospitalier Universitaire, 37 allées Jules-Guesde, 31000 Toulouse, France and 74 years, and $8.7 \% \geq 75$ years. Hydroxychloroquine indication was known in around $80 \%$ ICSRs: $37 \%$ in rheumatology, $21 \%$ in dermatology. The 3 main SMQs were hypersensitivity/allergic reactions, arthralgia and gastrointestinal ADRs. Retinal toxicity was found in $6.7 \%$ of ICSRs, cardiac arrhythmias (including 1.6\% torsades de pointes/QT prolongation) in $5.0 \%$, cardiomyopathy in $3.3 \%$ (Table 1). Deaths were reported in 221 patients (4.2\%), mainly women (76.0\%), $43.0 \%$ between 45 and 64 years. The first origin was cardiac disorders $(n=79)$. We found 65 poisonings, and 62 psychiatric and 54 respiratory disorders. Only 9 reports involved $\mathrm{H}+\mathrm{A}$ with 2 anaphylactic reactions without any death.

The present was performed to precise "serious" ADRs with hydroxychloroquine. It is the first study investigating these data in a worldwide perspective. The main ADRs were hypersensitivity and allergic reactions, arthralgia, and skin disorders. We also found the well-known ocular toxicity of hydrochloroquine after long-term use. Too few ADRs were reported with $\mathrm{H}+\mathrm{A}$ to allow any definite conclusion.

The most interesting results are the relative high percentage of cardiac ADRs (cardiomyopathy + arrhythmias $=8.3 \%$ of total ICSRs) showing that hydroxychloroquine, first, possesses a direct myocardic toxicity and, second, can disturb cardiac rhythm. The fact that reported deaths were more than one out of three times from cardiac origin is in agreement with this conclusion. The narrow therapeutic range of hydroxychloroquine [1] also explains the relative high percentage of poisoning. The present results also show that the cardiac signal (QT prolongation, arrhythmias...) found with hydroxychloroquine in COVID-19 patients [5, 6] was already present in patients with rheumatoid arthritis or lupus.

Another interesting result is the psychiatric ICSRs: $1.7 \%$ depression, $1.7 \%$ suicide, $1.3 \%$ psychosis. This could be another pharmacovigilance signal as recently suggested by the Spanish and French drug agencies [7].

Although suffering from the mandatory biases of such studies (underreporting, lack of systematic information on doses and duration exposure in Vigibase $\AA$, denominator 
Table 1 "Serious" Individual Case Safety Reports (ICSRs) registered in Vigibase® between 1 January 2010 and 31 December 2019 according to Standardised MedDRA Queries (SMQs) classification

\begin{tabular}{|c|c|c|}
\hline Number of "serious" ICSRs, SMQ (narrow) > 1\% & 5219 & $100.0 \%$ \\
\hline Hypersensitivity & 1229 & $23.5 \%$ \\
\hline Arthralgia & 882 & $16.9 \%$ \\
\hline Gastrointestinal (nausea, vomiting, diarrhea, constipation) & 727 & $13.9 \%$ \\
\hline Haemodynamic_oedema, effusions, fluid overload & 517 & $9.9 \%$ \\
\hline Retinal & 348 & $6.7 \%$ \\
\hline Cytopenia & 328 & $6.3 \%$ \\
\hline Non_infectious_diarrhea & 253 & $4.8 \%$ \\
\hline Haemorrhage ${ }^{-}$ & 216 & $4.1 \%$ \\
\hline Angioedema & 215 & $4.1 \%$ \\
\hline Infective pneumonia & 209 & $4.0 \%$ \\
\hline Shock & 194 & $3.7 \%$ \\
\hline Cardiac arrhytmias & 180 & $3.4 \%$ \\
\hline Cardiomyopathy & 172 & $3.3 \%$ \\
\hline Embolic thombotic event & 158 & $3.0 \%$ \\
\hline Cardiac failure & 143 & $2.7 \%$ \\
\hline Interstitial lung & 132 & $2.5 \%$ \\
\hline Arterial hypertension & 129 & $2.5 \%$ \\
\hline Agranulocytosis & 118 & $2.3 \%$ \\
\hline Hearing & 116 & $2.2 \%$ \\
\hline Gastrointestinal perforation & 112 & $2.1 \%$ \\
\hline Acute renal failure & 102 & $2.0 \%$ \\
\hline Depression & 90 & $1.7 \%$ \\
\hline Suicide & 89 & $1.7 \%$ \\
\hline Torsades de pointes/QT prolongation & 86 & $1.6 \%$ \\
\hline Rhabdomyolysis & 71 & $1.4 \%$ \\
\hline Psychosis & 66 & $1.3 \%$ \\
\hline Respiratory failure & 65 & $1.2 \%$ \\
\hline Acute central respiratory depression & 55 & $1.1 \%$ \\
\hline
\end{tabular}

unknown, use of hydroxychloroquine in rheumatic or autoimmune disorders and not COVID-19), the results have several important strengths: data in the context of real world not studied in clinical trials, study performed in the world's largest pharmacovigilance database from around 130 countries allowing generalization of results.

Acknowledgements The authors acknowledge the WHO Uppsala Monitoring Center that allowed the authors' access to Vigibase ${ }^{\circledR}$. The conclusions of the authors are not necessarily those of the WHO Uppsala Monitoring Center or the French Drug Agency (Agence Nationale De Sécurité du Médicament et des produits de santé, ANSM).

\section{Compliance with ethical standards}

Conflict of interest The authors declare that they have no conflict of interest.

\section{References}

1. Vinetz JM (2018) Chemotherapy of malaria. In Goodman and Gilman's the pharmacological basis of therapeutics. Eds LL. Brunton, R. Hilal-Dandan, BJ. Knollmann. Mc Graw Hill New York 13th edition. 968-86
2. Lenzer J (2020) Covid-19: US gives emergency approval to hydroxychloroquine despite lack of evidence. BMJ 369:m1335

3. Roustit M, Guilhaumou R, Molimard M, Drici MD, Laporte S, Montastruc JL (2020) Chloroquine and hydroxychloroquine in the management of COVID-19: much kerfuffle but little evidence. Therapie. https://doi.org/10.1016/j.therap.2020.05.010

4. Bihan K, Lebrun-Vignes B, Funck-Brentano C, Salem JE (2020) Uses of pharmacovigilance databases: an overview. Therapie. https://doi.org/10.1016/j.therap.2020.02.022

5. Chorin E, Day M, Shulman E et al The QT in patients with COVID-19 treated with hydroxychloroquine and azithromycin. Nat Med. https://doi. org/10.1038/s41591-020-0888-2

6. Gerard A, Romani S, Fresse A et al. (2020) "Off" label use of hydroxychloroquine, azithromycine, lopinavir-ritonavir and chloroquine in COVID-19: a survey of cardiac adverse drug reactions by the French Network of Pharmacovigilance Centers. Therapie 2020, https://doi.org/ 10.1016/j.therap.2020.05.002

7. French Drug Agency. Médicaments utilisés chez les patients atteints du COVID-19 : une surveillance renforcée des effets indésirables. Point d'information. https://ansm.sante.fr/S-informer/Actualite/ Medicaments-utilises-chez-les-patients-atteints-du-COVID-19-unesurveillance-renforcee-des-effets-indesirables-Point-d-informationactualise-le-14-05-2020 accessed 19th May 2020

Publisher's note Springer Nature remains neutral with regard to jurisdictional claims in published maps and institutional affiliations. 